\title{
PRÁTICAS INOVADORAS COM TECNOLOGIAS DIGITAIS NA FORMAÇÃO INICIAL DE PROFESSORES
}

\author{
INNOVATIVE PRACTICES USING DIGITAL TECHNOLOGIES IN THE \\ INITIAL TEACHER EDUCATION
}

\author{
Nielce Meneguelo Lobo da Costa \\ Universidade Anhanguera da São Paulo - UNIAN \\ nielce.lobo@,anhanguera.com \\ Maria Altina da Silva Ramos \\ Universidade do Minho - UMINHO \\ altina@ie.uminho.pt
}

\begin{abstract}
Resumo
Na pesquisa que subsidia este artigo se investiga a prática pedagógica de docentes universitários atuantes na formação inicial de professores na Licenciatura em Educação Básica e/ou Mestrado na Educação pré-escolar e Ensino no primeiro Ciclo do Ensino Básico, em Portugal, quanto ao uso de Tecnologias Digitais da Informação e Comunicação (TDIC) para o ensino e a aprendizagem. A metodologia é a qualitativa, com base na Teoria Fundamentada nos Dados (Grounded Theory GT) e a coleta de dados foi feita por entrevista semiestruturada a professores universitários experientes em uso de TDIC na prática docente e tidos como inovadores por seus pares. A análise interpretativa segue técnicas sugeridas pela GT, sendo a categoria fundamental "inovação na formação inicial docente" e as categorias axiais: "sobre estratégias didáticas", "sobre recursos tecnológicos" e "sobre planejamento e gestão de aula". O artigo discute estratégias didáticas de dois dos entrevistados, que são professores licenciados em Matemática. Como resultados, identificamos características da prática dos docentes ligadas à realidade do exercício da docência de ambos e, quanto às TDIC, elas estão presentes na prática principalmente pelo uso de softwares e de jogos específicos para o ensino de Matemática nos anos iniciais de escolaridade.
\end{abstract}

Palavras-chave: Prática docente; Inovação; Recursos Tecnológicos.

\begin{abstract}
The research that supports this article investigates the pedagogical practice of university professors working in the initial formation of teachers in the Basic Education Degree and / or Master in Preschool Education and Teaching in the First Cycle of Basic Education, in Portugal, regarding the use of Digital Information and Communication Technologies (DICT) for teaching and learning. The methodology is qualitative, based on Grounded Theory (GT) and data collection was done through semi-structured interviews with university teachers experienced in using DICT in teaching practice and considered as innovative by their peers. The interpretative analysis follows techniques suggested by the WG, being the fundamental category "innovation in initial teacher education" and the axial categories: "about didactic strategies", "about technological resources" and "about
\end{abstract}


planning and classroom management". The article discusses didactic strategies of two of the interviewees, who are licensed teachers in Mathematics. As results, we identified characteristics of the teachers' practice related to the reality of the teaching practice of both and related to DICT into the practice, it occurs mainly using specific software and games for the teaching of mathematics in the early years of schooling.

Keywords: Teaching practice; Innovation; Technological Resources.

\section{APRESENTAÇÃO}

Docentes universitários atuantes na Licenciatura em Educação Básica e no Mestrado na Educação pré-escolar e Ensino no primeiro Ciclo do Ensino Básico são os responsáveis, em Portugal, pela formação inicial de professores que atuarão nos anos iniciais da escolaridade, lecionando para crianças de 3 a 10 anos. Isso significa que, são eles que formarão os alunos nascidos no século XXI e que são os incumbidos pelos primeiros contatos dessas crianças com o conhecimento escolar, auxiliando-as na construção de diversos dos conceitos científicos (LOBO DA COSTA, 2019). Para tanto, entre as competências profissionais, esses futuros professores devem desenvolver conhecimentos na formação inicial que os levem a construir referenciais para suas práticas didáticas que sejam coerentes com as necessidades das novas gerações e que eles irão guiar com as novas formas de aprender dos alunos desta era.

O século atual apresenta os grupamentos humanos e a sociedade em geral cada vez se tornando mais complexos e caracterizados pela rápida circulação de informações, pelas mudanças cada vez mais aceleradas e com as certezas cada vez menos estabelecidas. Como apontado por diversos pesquisadores, no limiar do século XXI, a intitulada "sociedade informacional" por Tofller (1990), "sociedade em rede" por Castells (1999), "sociedade do conhecimento" por Lyotard (1998) e "sociedade da informação" por Reding (2006) é caracterizada pela forte presença das TDIC, que estão, cada vez mais se complementando, disponibilizando novas formas de ação e comunicação. Enfim, como indicaram Lobo da Costa, Prado e Kfouri (2017), mudando o "modus operandi" do indivíduo ao atuar na sociedade, no mundo do trabalho e na vida pessoal

Os futuros professores que atuarão nos anos iniciais de escolaridade das crianças, precisam se apropriar e aprender a utilizar o computador e a tecnologia como ferramenta cognitiva, como defende (Jonassen, 2000). As TDIC introduzem novas linguagens e procedimentos integrantes do dia-a-dia dos alunos que "já chegam com o pensamento estruturado pela forma de representação propiciada pelas novas tecnologias. Portanto, 
utilizá-las é se aproximar das gerações que hoje estão nos bancos das escolas". (ALMEIDA, 2010).

Entre as competências profissionais docentes está hoje a chamada "competência digital", dada a necessidade de que os professores sejam, não apenas usuários eficientes das TDIC, mas que façam uso dos recursos tecnológicos para os processos de ensino e de aprendizagem. Em 2008 a Unesco, no documento "ICT competency standards for teachers", já alertava para a premência de se desenvolver nos docentes a capacidade de serem usuários eficientes das TDIC, de modo a navegarem pela internet por meio dos diversos buscadores e aí selecionar, analisar e avaliar informações que lhes subsidiassem nas tomadas de decisão e os auxiliassem na produtividade, na comunicação, na colaboração, na edição e produção. (UNESCO, 2008). Documento mais recente sobre competências docentes, lançado pelo Centro de Pesquisa da Comissão Europeia, em 2017, o "European Framework for the Digital Competence of Educators: DigCompEdu" ampliou assim o escopo da competência digital indicando entre as competências profissionais docentes, as seguintes: 1) usar recursos digitais para a seleção, a criação e a adaptação de atividades didáticas, para a gestão, a proteção, o resguardo e o compartilhamento de informações e, 2) promover o desenvolvimento da competência digital dos aprendizes. (REDECKER, 2017).

Neste cenário, destaca-se a importância de que a formação inicial docente propicie oportunidades de o futuro professor utilizar os recursos digitais na perspectiva apontada pelo Relatório DigCompEdu e oportunidades para que ele possa desenvolver a competência digital de seus alunos vindouros. Contudo, pesquisas na área têm apontado a ausência de Tecnologia Educativa em cursos de Pedagogia e a percepção de despreparo pelos finalistas no tocante à capacidade de promover a literacia digital das crianças (MARINHO, 2007); (MOREIRA, RAMOS, LOBO DA COSTA, 2018).

Estudos, como por exemplo o de Figueiredo (2017), evidenciam que muitos professores de Matemática oferecem aos seus alunos quase sempre um espaço educativo marcado pela reprodução de métodos e estratégias didáticas que eles mesmos vivenciaram quando foram formados. Isso ocorre pois, entre outras causas, há a tendência do ser humano em atuar na sua "zona de conforto", que é conceituada como sendo psiquicamente constituída por comportamentos e rotinas individuais estabelecidas porque levaram ao sucesso do indivíduo na realização de tarefas, no enfrentamento de situações diversas e no 
lidar com emoções e experiências afetivas. Para a pessoa os comportamentos padronizados minimizam os níveis de estresse e ansiedade pela previsibilidade e sensação de controle, o que valida a repetição de atitudes e comportamentos já consolidados.

Borba e Penteado (2001) alertam para as dificuldades de os professores saírem da sua "zona de conforto" na docência, o que resulta em repetição de estratégias didáticas familiares a eles. O processo de inovar em sala de aula pode estar ligado às experiências inovadoras que foram experimentadas pelo professor quando aluno dos cursos de formação inicial e/ou continuada. Assim, os licenciandos devem ter oportunidades de serem produtores de conhecimento, em vez de apenas receptores de informações, afinal estão em uma sociedade que valoriza a autoria, a criatividade e a autonomia.

A implementação de processos de inovação pedagógica no Ensino Superior, especialmente aqueles articulados às tecnologias digitais, estão intimamente conectados às possibilidades de os docentes resolverem sair dessa "zona de conforto" e ousarem implantar mudanças e transformações na prática de ensinar, particularmente, modificando as metodologias que utilizam. Atuar na docência sem ousadia, sem abertura para a experimentação e o novo apresenta "o risco de continuar oferecendo, em pleno século XXI, uma educação do século XIX, de estar fazendo, em plena Idade Mídia, uma educação que mais lembra a da Idade Média”. (GROSSECK, MARINHO, TÁRCIA, 2009, p. 121).

Questões fundamentais para a inovação pedagógica na docência se ligam à figura dos professores, às possibilidades que eles tenham para implementar as inovações que pretendem e, ainda, para a prática de ensinar com novas metodologias, em particular, com o uso das tecnologias digitais.

Isso posto, fica a indagação: Como professores universitários têm oferecido espaços de aprendizagem para desenvolver em seus estudantes (os futuros professores) competências docentes para este século? Quais são as estratégias didáticas que têm sido experimentadas ao longo da formação inicial pelos futuros professores? Como se está a preparar futuros professores para o uso de metodologias de ensino com tecnologias digitais de modo a propiciar ao aluno oportunidades de aprender e construir de forma ativa seu conhecimento, tirando proveito da tecnologia como uma ferramenta para o pensamento?

Em síntese, a problemática da pesquisa é a de como se está a preparar no Ensino Superior, na formação inicial, os futuros professores dos primeiros anos de escolaridade, de modo que esses experienciem estratégias didáticas diversificadas, incluindo o uso das 
tecnologias digitais integradas à metodologias ativas de ensino, com a intenção de construírem referenciais para a prática docente.

Neste artigo apresentamos um recorte de uma pesquisa maior, a qual investiga como professores universitários adequam os ambientes e os espaços de aprendizagem para desenvolver em seus estudantes (os futuros professores) competências docentes para este século. No recorte nos propomos a analisar práticas inovadoras com tecnologias digitais de dois docentes licenciados em Matemática, aplicadas na formação inicial de professores, identificadas em entrevistas.

\section{FUNDAMENTAÇÃO TEÓRICO-METODOLÓGICA}

A fundamentação teórica da pesquisa envolve construtos sobre: Inovação pedagógica e sobre Metodologias ativas de ensino, com o uso de tecnologia digital. Os construtos teóricos nos subsidiaram na criação dos instrumentos de coleta de dados.

Inovação é um conceito muito estudado na área da Administração, por seu caráter impactante no desenvolvimento e viabilidade econômica nas Organizações. Inovação é o processo a partir do qual, nas empresas, se introduzem mudanças capazes de efetivar novos procedimentos, disponibilizar diferentes serviços e enfrentar desafios de atualização e competitividade (DRUCKER, 2000). Naturalmente, esse processo depende e se desenvolve por meio dos indivíduos, das equipes, dos times atuantes nas Organizações. São as pessoas inovadoras, como definem Kelley e Litman (2007), aquelas que aprendem, organizam, constroem. Isto significa dizer que inovadores são indivíduos que têm boas ideias e as colocam em prática, são empreendedoras, executam as ações necessárias para transformar a ideia em resultado. Para inovar é necessária uma combinação de sinergia e inteligência, mas também é preciso condições de estrutura organizacional e um ambiente de acolhimento, confiança, suporte e rapidez de decisões.

$\mathrm{Na}$ Educação, a inovação, particularmente na prática pedagógica, se liga ao desenvolvimento de formas de ensino e de aprendizagem que são diferentes das convencionais nas escolas. A inovação pedagógica envolve uma ruptura com vivências anteriores de ensino e de aprendizagem e, sobretudo, com o paradigma de transmissão, característico da sociedade industrial. A partir da reflexão crítica do docente sobre os processos pedagógicos, é que ele pode passar a criar cenários de aprendizagem com 
modificações nos papéis característicos de aluno - receptor e de professor - emissor.

No dia-a-dia da profissão docente é difícil empreender a mudança para privilegiar os alunos de hoje que vivem uma realidade completamente diferente da dos professores quando estes eram alunos. No entanto, para abordar esse tema de forma real é necessário um novo enfoque para as ações a serem desenvolvidas visando à formação docente, mesmo porque professores formadores têm facilidade em ensinar teorias, mas muitas vezes não têm a mesma facilidade para discutir ações para e sobre a prática. A prática docente hoje pode se beneficiar de metodologias nas quais o aluno tem um papel de protagonista, são as chamadas metodologias ativas.

Estratégias didáticas que envolvem o uso de metodologias de ensino, nas quais o aluno tem um papel de protagonista, podem ser uma forma importante para a inovação do Ensino Superior, impulsionando a aprendizagem dos estudantes. São exemplos de metodologias ativas: a aprendizagem baseada em projetos (Project Based Learning), a aprendizagem por resolução de problemas (Problem Based Learning), a sala de aula invertida (Flipped Classroom), os estudos de caso (Case Studies), jogos (Gameficação), aprendizagem em grupos etc. Entretanto, como alerta Beck (2018, s/n), “As metodologias ativas estão muito relacionadas com a postura do educador, da forma de avaliação e de como são valorizadas as experiências prévias dos participantes", ou seja, cabe ao professor, por meio das estratégias didáticas em uso, fazer com que o aluno participe ativamente das aulas.

Em relação às tecnologias digitais e seu papel nas metodologias ativas de aprendizagem, pressupomos que este se vincula às abordagens que privilegiam o desenvolvimento de atitudes ativas no aluno e a vivência de situações investigativas no processo de aprendizagem.

A metodologia da pesquisa maior que subsidia este recorte é de cunho qualitativo, com características da Teoria Fundamentada nos Dados - Grounded Theory (GT), a qual busca decifrar a realidade a partir das informações dela retiradas, sem a preocupação de testar teorias já estabelecidas ou de confirmar hipóteses. A GT é um tipo de metodologia de pesquisa que foi desenvolvida para as Ciências Humanas e Sociais por Glaser e Strauss em 1967 (TAROZZI, 2011). Trata-se de uma metodologia qualitativa que busca "gerar de forma indutiva ideias teóricas novas ou hipóteses a partir dos dados, em vez de testar teorias especificadas de antemão", como ensina (GIBBS, 2009, p. 71). O pesquisador vai a campo 
sem ideias pré-concebidas e, com as evidências recolhidas nos dados "procura determinar qual o significado simbólico dos factos para os intervenientes no fenómeno em estudo" (COUTINHO, 2011, p. 302). Assim, em pesquisas pautadas na GT não se busca confirmar teorias pré-existentes ou analisar os dados a partir de um determinado enfoque teórico

A investigação foi dividida em três fases: uma de Pesquisa bibliográfica e análise documental; outra de Pesquisa em campo, na qual foram empreendidas entrevistas a docentes do Ensino Superior e, por último, a terceira fase, de nova revisão bibliográfica e análise de dados. A coleta da fase da Pesquisa em campo foi feita por meio de entrevista semiestruturada aplicada individualmente aos docentes participantes. O material coletado durante o projeto, no caso as gravações em áudio das entrevistas, as transcrições e os registros escritos com as notas da pesquisadora, são de uso exclusivo desta pesquisa. Os participantes tiveram seus nomes trocados por pseudônimos preservando a identidade em sigilo; eles assinaram um Termo de Consentimento Livre e Esclarecido conforme especificações da Ética na pesquisa.

Quanto à coleta de dados, consideramos que a técnica mais adequada para tanto seja a entrevista semiestruturada, uma vez que ela é fonte de significados e pode revelar aspectos nem sempre observáveis por outras formas. A entrevista permite entrar na perspectiva do entrevistado, especialmente quando se cria um clima no qual ele se sinta seguro e confortável para expressar suas opiniões, relatar sobre seu mundo profissional e seu fazer pedagógico. Entretanto, temos consciência de que a qualidade da entrevista e, consequentemente, dos dados obtidos por meio dela dependem essencialmente do entrevistador, ao selecionar antecipadamente as questões e ao conduzir a entrevista.

Optamos pela técnica de entrevista do tipo semiestruturada. Esta caracteriza-se pela existência de um guião previamente preparado que serve de eixo orientador ao desenvolvimento da entrevista. Por meio desse guião se procura garantir que os diversos participantes respondam às mesmas questões. Contudo, não se exige uma ordem rígida nas questões, mas que todas sejam cobertas na entrevista, ou seja, este guião funciona como um checklist e no desenrolar da entrevista se vai-adaptando ao entrevistado a ordem de colocação das questões e mesmo o acréscimo de outras indagações. Assim, mantém-se um elevado grau de liberdade na exploração das questões.

Entendemos, seguindo Mattos (2005), que os pontos fortes da entrevista semiestruturada são os seguintes: optimização do tempo disponível; tratamento mais 
sistemático dos dados; a possibilidade de selecionar temáticas para aprofundamento e a introdução de novas questões ao longo da entrevista, caso seja necessário, embora não se espere tal inserção, não se estabelece a rigidez das questões.

Os participantes foram seis docentes universitários que lecionam na Licenciatura em Educação Básica e/ou Mestrado na Educação pré-escolar e Ensino no primeiro Ciclo do Ensino Básico em uma universidade no norte de Portugal. O critério de inclusão foi o de serem professores universitários experientes em formação inicial de futuros professores; conhecidos como desenvolvedores de práticas inovadoras, e com histórico de praticarem o ensino com o uso de tecnologia digital, sobretudo o uso pedagógico da tecnologia digital e, além disso, consentirem em participar voluntariamente da pesquisa.

Os dados foram coletados por meio de entrevistas semiestruturadas feitas individualmente a seis docentes, entretanto neste texto, devido à limitação própria de um artigo, apresentamos análise de dados de duas das entrevistas. No caso, as entrevistas dos dois docentes que são os responsáveis pelas disciplinas de Ensino de Matemática e de Ensino de Ciências nas formações iniciais de Licenciatura em Educação Básica da instituição portuguesa na qual se realizou a pesquisa.

Nas entrevistas procurou-se obter informações sobre as práticas didáticas dos docentes, quais as metodologias de ensino que utilizam nas aulas e como inserem as tecnologias digitais para ensinar. Para tanto, o guião da entrevista semiestruturada foi elaborado em blocos, incluindo questões para levantar características: 1) do docente, identificando a formação inicial e verificando a existência de oportunidades de formação continuada; 2) da prática pedagógica, identificando traços de inovação por: atividades, projetos ou experiências que tenha realizado em aula; 3) do uso pedagógico da tecnologia, identificando o papel que a tecnologia exerce na prática pedagógica do docente; 4) do embasamento teórico de suas práticas e 5) do conhecimento teórico e prático acerca das metodologias ativas de ensino e aprendizagem, e, em particular, da sala de aula invertida, com o uso de tecnologia digital.

Enfatizando, com o primeiro bloco de questões o objetivo foi conhecer a formação de origem do docente; verificar se houve nela algum tipo de formação pedagógica/didática; identificar se a formação acadêmica do entrevistado é específica para lecionar, se possui mestrado/doutorado, na área da Educação ou do Ensino. O bloco 2 se propôs a identificar estratégias pedagógico-didáticas do docente entrevistado, tais como, atividades, projetos e 
experiências que desenvolve com os estudantes. O bloco 3 procurou identificar o papel que a tecnologia exerce na prática do docente e identificar características da prática do docente: estratégias pedagógico-didáticas envolvendo tecnologia (identificar o uso pedagógico das tecnologias). No bloco 4 a intenção foi compreender o embasamento teórico da prática do docente e o último bloco, o 5, intentou identificar a concepção de Metodologia ativa de ensino do docente, especificamente as que utilizam tecnologias digitais, assim como sua concepção da metodologia de Sala de aula invertida e identificar o uso por ele.

A análise interpretativa se desenvolveu, por categorias emergentes, como sugerem Strauss e Corbin (1990, citados por Gibbs, 2009) quanto às técnicas de análises de dados em pesquisas na metodologia da Grounded Theory. Os dados foram tratados em três etapas: codificação aberta, codificação axial e codificação axial com a categoria fundamental. Na etapa de codificação aberta foi realizada a leitura dos dados e identificadas as categorias relevantes, com comparações efetuadas por técnicas de inversão; na etapa da codificação axial houve um refinamento das categorias identificadas e agrupamos os dados em eixos e, na terceira etapa, de codificação axial com a categoria fundamental, procurou-se identificar uma categoria predominante ou aglutinadora que se tornou a categoria fundamental e a partir dessa se estabeleceu o relacionamento ou conexão com as demais categorias identificadas.

Na pesquisa em discussão, a categoria fundamental identificada - à qual as demais se relacionam - foi "inovação na formação inicial docente". As categorias axiais emergentes foram: "Sobre as estratégias didáticas", "Sobre recursos tecnológicos" e "Sobre planejamento e gestão de aula" todas elas conectadas à categoria fundamental. Foram esses os eixos analíticos que auxiliaram a identificar a prática didática dos docentes universitários entrevistados, as metodologias de ensino que utilizam e como ocorre a integração de tecnologias digitais nas disciplinas do Ensino Superior ministradas por eles. Desta forma procuramos vislumbrar como se está a preparar no Ensino Superior, na formação inicial, os futuros professores dos primeiros anos de escolaridade.

\section{DISCUSSÃO}

Neste artigo centramos a discussão em duas das entrevistas realizadas na pesquisa: a da professora Alícia e a do professor Fabiano, aqui referenciados por pseudônimos para garantir o anonimato. 
Alícia cursou a licenciatura em Matemática na Faculdade de Ciências do Porto e relata que teve poucas cadeiras [disciplinas] de cunho educacional. Lembra-se de que cursou Didática da Matemática, de responsabilidade do departamento de Matemática que, em verdade, abordou álgebra, sem relação com Didática propriamente dita. Já os departamentos de Educação e de Psicologia asseguravam cadeiras de Pedagogia, entretanto relatou que dessas se recorda apenas que teve Sociologia da Educação. Em suas palavras: "era de fato um modelo bastante diferente muito focado na matemática pura". Acrescentou que no Estágio de docência foi necessário apresentar um trabalho científico para o supervisor da faculdade e que este nada tinha a ver com prática docente. No seu caso, pesquisou linhas cáusticas, o que não tem qualquer aplicação no ensino de Matemática na Educação Básica. Alícia cursou mestrado em Matemática Aplicada, novamente sem conexão com o ensino, contudo, foi a partir de lecionar Matemática no Ensino Superior que percebeu que o queria mesmo era ensinar, daí fez doutoramento em Matemática Elementar e Didática de Matemática. Sobre sua trajetória profissional, ela acrescenta: "meu caminho, acabou por ter umas curvas no percurso até chegar ao ponto que eu acho que devia estar, faz agora em dezembro 22 anos que aqui estou", (...) "na licenciatura em Educação Básica e em vários mestrados em Ensino, desde o pré-escolar ao segundo ciclo, mas não na licenciatura em Matemática".

Ressalvamos que a professora Alícia tem formação específica em Matemática, com conhecimentos aprofundados em Ensino de Matemática Elementar e em Didática da Matemática, esta última sendo a área de pesquisa de seu doutoramento. Sua prática é considerada pelos pares e pelos alunos como inovadora e com utilização de tecnologia digital, entretanto, nos relatou que não foi preparada em Tecnologia Educativa e que somente participou de alguns workshops em congressos da área de Educação Matemática, os quais abordaram o uso de tecnologia para ensinar. Ela compôs por conta própria suas estratégias de ensino, por meio de pesquisas e iniciativa de uso de softwares e demais recursos tecnológicos.

Fabiano cursou Licenciatura em Ensino da Matemática na universidade onde hoje atua. Logo após a conclusão do curso efetivou-se como professor em escola de Ensino Secundário e lá lecionou durante dez anos. Nessa escola acompanhou e orientou licenciandos nos Estágios supervisionados de docência. A partir dessa experiência com estagiários foi convidado a atuar como docente no curso de Licenciatura em Matemática 
na Universidade. Fabiano deixou então o Ensino Secundário e foi lecionar como professor universitário na condição de assistente convidado. Cursou então o mestrado, pesquisando a "Supervisão Pedagógica em Ensino de Matemática" e o doutorado, em Didática da Matemática. Fabiano hoje é professor e pesquisador, na mesma instituição onde iniciou a lecionar no Ensino Superior e, também, onde cursou o mestrado e o doutorado.

O professor Fabiano teve como primeira formação acadêmica a Licenciatura em Ensino da Matemática, portanto específica para a docência. Foi estudante na própria universidade onde leciona e não tinha na família alguém que o tivesse sensibilizado para ser professor de Matemática, como muitas vezes está apontado na literatura. Para Fabiano, após a conclusão da licenciatura foi fácil, na época, efetivar-se como professor do Ensino Secundário, na própria cidade onde se localiza a Universidade, independentemente das notas obtidas no curso, algo que não é agora possível. Ele permaneceu na mesma escola por uma década. Esta escola dava apoio ao licenciandos para a realização do Estágio supervisionado de docência, abria as portas aos estagiários da Licenciatura em Matemática, que deveriam ser orientados pelos seus docentes. Assim surgiu a oportunidade de atuar na orientação dos estagiários e nesse papel, Fabiano estabeleceu uma interlocução com o supervisor da universidade e recebeu o convite para atuar como docente no curso de Licenciatura em Matemática na universidade. Fabiano solicitou então dispensa do Ensino Secundário e iniciou como professor do Ensino Superior, como professor assistente convidado. O próximo passo foi cursar de forma gratuita o mestrado, uma vez que era docente da instituição, investigando o tema "Supervisão Pedagógica em Ensino de Matemática". A conclusão do mestrado foi em 2000 e na sequência veio o doutoramento em Didática da Matemática, concluído em 2008. Ele continua até hoje como professor e pesquisador, na mesma instituição onde iniciou a lecionar no Ensino Superior.

Observamos que o professor Fabiano tem formação específica para o ensino de Matemática, com conhecimentos aprofundados sobre a atuação docente no Ensino Secundário e sólida formação em Didática. Ele atua como docente há mais de 10 anos na Universidade em que se formou na Licenciatura em Matemática. Atualmente ministra a disciplina de "Complementos de Matemática e Ciências para a Infância".

Observamos que, como Alícia, o professor Fabiano tem formação específica em Matemática. Tem conhecimentos sobre atuação no Ensino Secundário e sólida formação em Didática. Apesar de ser docente conhecido na universidade por ensinar de forma 
inovadora e com utilização tecnologia digital, perguntado sobre como desenvolveu essa capacidade, ele esclarece que não teve qualquer formação (inicial ou continuada) para isso, apenas frequentou uma ação de formação para uso do SPSS, no caso, pela necessidade de orientar mestrandos que iriam utilizar tal software no tratamento de dados. Quanto aos demais softwares que utiliza na docência, tais como o GeoGebra, o Sketchpad, o Cabri, etc, declara que aprendeu de forma autónoma, por tentativa e erro, decidindo ponto a ponto o que integrar na sua prática. Nesse aspecto há uma proximidade entre os dois docentes.

Ambos tiveram como primeira formação a Licenciatura em Matemática e se dedicaram à Didática da Matemática no doutorado. As tecnologias digitais foram se incorporando paulatinamente à prática a partir de esforços próprios e tentativas do tipo ensaio e erro.

$\mathrm{Na}$ sequência passamos a discutir as características da prática desses professores universitários, responsáveis pela formação inicial docente.

\section{Inovação na formação inicial docente}

A categoria fundamental de análise foi a de "inovação na formação inicial docente". Foi possível identificar que as principais estratégias didáticas presentes na prática de Alícia são: a proposição de problemas e o uso de materiais manipulativos. A resolução de problemas é utilizada pelo desafio que ela apresenta aos estudantes e os materiais manipulativos por entender que eles são fundamentais para ensinar matemática às crianças e, em consequência, é necessário que os futuros professores os utilizem durante sua formação inicial e não apenas saibam que eles existem. Isto significa dizer que, para Alícia, levar os futuros professores a vivenciarem a forma como um material concreto pode funcionar para o ensino e a aprendizagem de Matemática deve fazer parte da formação docente. Segundo a professora:

Nós temos uma sala de recursos, com materiais manipuláveis que se pode utilizar, (...), porque os alunos podem de fato ter os materiais, ir buscar até para ilustrar alguma coisa que queiram fazer. Nem sempre isso acontece, (...) o problema não é tanto a sala, é a forma como eles trabalham nessa sala.

A tecnologia digital tem sido utilizada pela professora Alícia para levar o aluno a explorar situações da resolução de problemas. Por exemplo, ao lecionar transformações geométricas considera imprescindível usar o Geogebra e não apenas os recursos de papel e lápis, pois no software é possível movimentar as figuras e investigar propriedades, "com 
o papel e lápis isso não funciona, pois não se pode mexer, já não dá para mudar, serve [o software] para eles explorarem as figuras, explorarem o conceito em uso". Alícia ressalta que ao ensinar matemática "a parte expositiva [é relevante] em certas aulas de fato é preciso expor a matéria e os alunos vão mais ou menos interagindo comigo", então fica evidenciado que há uma mescla de momentos com os alunos em ação e momentos de exposição de conteúdos pela docente e de sistematização de ideias.

Ambos os professores (Alícia e Fabiano) relataram que as estratégias didáticas utilizadas dependem muito das particularidades da disciplina que estão lecionando.

A entrevista com Fabiano revelou que para ele, assim como para Alícia, uma estratégia didática muito utilizada é a proposição de problemas. Ele utiliza os procedimentos básicos do Modelo de Polya ${ }^{1}$ “(...) porque eu penso que como estou a formar futuros educadores e professores, importa trabalhar com esse Modelo para que eles depois apliquem ou repliquem na sua sala de aula". Dessa forma, procura levar os licenciandos a desenvolverem a capacidade de resolução de problemas, ensinando os procedimentos básicos do Modelo de Polya de modo que, com a aprendizagem, os alunos estejam instrumentados para a resolução de problemas. "Apercebo-me que a ênfase que estou a dar, [...] é aquela ideia das fases do Polya e de suas heurísticas. Os futuros professores têm uma tendência de resolver problemas tipo "saca-rolhas", sem ter uma estratégia delineada, sem analisar o que o enunciado tem, o que é que está a omitir, o que é que eu preciso saber, e tal".

Fabiano explicou que usa muito tarefas de investigação e, para os alunos as desenvolverem, propõe explorações com softwares, jogos e simuladores. Assim, (...) procuro que eles resolvam de uma forma individual ou em pares, portanto, uma das características do ensino exploratório, é que eles exploram a tarefa, numa primeira

\footnotetext{
${ }^{1}$ Polya, em seu livro "A arte de resolver problemas", publicado em 1945, apresentou um método para ser utilizado quando alguém enfrenta um problema e as etapas a serem seguidas para resolvê-lo e, ainda, discutiu no texto sobre como ensinar a resolver problemas. No método, ele apresenta quatro fases de resolução, que são: compreensão do problema, estabelecimento de um plano de ação, execução do plano e retrospecto. Na fase de compreensão do problema é fundamental identificar dados, incógnita e condicionante, além de se familiarizar com o enunciado. Ao estabelecer o plano de ação, ensina que se deve considerar problemas auxiliares, se não for possível identificar uma estratégia imediata de resolução, procurar conexões entre os dados e a incógnita e identificar problemas conhecidos que possam subsidiar na resolução. Ao executar o plano de ação, procurar identificar se cada passo dado está correto e, por último, na fase de retrospecto, procura-se verificar a validade do resultado obtido e analisa-se possíveis caminhos alternativos de resolução e se a estratégia utilizada pode ser generalizada para outros tipos de problemas. Para mais detalhes sobre Resolução de problemas em Educação Matemática ver Onuchic e Allevato (2011).
} 
instancia clarificamo-la o que é que nos dá, o que é que nos pede, deixo resolver, depois há uma discussão no grupo/turma..." Conclui-se que Fabiano se preocupa em propiciar oportunidades de aprendizagem individual, de modo que o estudante assimile as informações e as acomode, construindo os conceitos. Também promove aprendizagem coletiva, a partir das interações entre os estudantes. Nesse sentido, procura promover ensino exploratório e estimular discussões entre professor e aluno e entre aluno e aluno. (...) analisamos quais são os conteúdos que precisamos [na resolução do problema], o que é que está esquecido e falta lembrar, quais são as estratégias de resolução dos problemas propostos, quem usou estratégias diferentes, qual é a tipologia do problema. Uma vez resolvido o problema, Fabiano enfatiza que há ainda a fase da validação dos resultados obtidos, o que envolve uma análise do problema e de suas características.

A ênfase dada foi em como desenvolver conhecimentos matemáticos no aluno, no caso conhecimento especializado do conteúdo.

O prof. Fabiano acrescenta:

É um desafio terrivel, para mim e para eles. Quando chega em certos problemas que temos de provar os resultados, no caso da indução matemática... Por mais que se fale da metáfora das peças de dominó, basta que a primeira caia que as demais vão caindo em sequência até a última também cair, portanto, faz assim algumas encenações e a coisa tem corrido bem, mas aquilo é um caráter abstrato mas eu acho que é importante que eles percebam da necessidade de provar resultados e os generalizar.

Concluímos que ele está investindo em levar os estudantes a perceberem a necessidade de validação da resposta obtida e de procedimentos de generalização. Além disso, procura dar voz e protagonismo ao aluno, sempre que possível.

Como pode-se observar pelo excerto anterior, o professor Fabiano, que é considerado e aclamado na instituição como inovador e muito bem visto pelos alunos por sua criatividade e disponibilidade, declarou que para ele é um grande desafio utilizar a metodologia de ensino por resolução de problemas. O que ratifica que não é simples inovar na docência, a inovação pedagógica necessita coragem e tempo do professor.

Para ele, tudo: "depende muito da cultura do próprio aluno, porque nós sabemos, em Matemática, e nós somos culpados em parte, habituamos os alunos a receber, não é? Aquela ideia de transmissão. E o aluno cria a ideia de que se o professor não diz tudo é um fraco professor. É um dilema..."

Fabiano apresenta o dilema que enfrenta o professor de Matemática ao resolver inovar, que é o modificar a estrutura da aula sob pena de ser considerado um professor 
ineficiente. Isso porquê o aluno está habituado a que lhe sejam transmitidas todas as informações necessárias para a resolução das tarefas e problemas, uma vez que, no ensino convencional, a postura do aluno é a de receber e o professor é o responsável por organizar as informações e colocá-las na lousa de forma clara e precisa para que o estudante as anote e, em seguida, utilize nos exercícios e tarefas. Na verdade, quando utilizamos metodologias ativas no ensino e deixamos na mão do aluno o protagonismo, ele pode interpretar que não sabemos ensinar ou não estamos querendo ensinar.

Concluímos que na concepção do professor entrevistado, as estratégias didáticas e a metodologia de ensino aplicada são condicionadas por diversos fatores. Dependem muito do saber que se está a ensinar e da carga horária da disciplina, pois a utilização de uma metodologia ativa pode levar, por vezes, ao risco de não cumprir os conteúdos curriculares prescritos. Fabiano declara: Na prática procuro inverter o processo. Já procuro puxar por eles e quem vai ao quadro e quem faz as coisas são eles. Eu só estou ali a dar dicas. (...) O professor tem que saber gerir as diferentes estratégias em função dos alunos que tem, que é importante, e em função, também da disciplina.

Segundo Alícia, ela ministra aulas práticas, que acontecem em uma sala equipada com recursos diversos, nessas, organiza a sala em grupos, particularmente para resolver problemas, participar em jogos, ou explorar softwares em um conjunto de atividades. Nesse caso a interação é entre ela e cada grupo, com sua particular tarefa.

Sobre estratégias didáticas com recursos tecnológicos na prática, ela acrescenta:

Eu basicamente uso ou Geogebra, usei já com alunos pré-escolar, $1^{\circ}$ ciclo, mas no $1^{\circ}$ ciclo acrescento linguagem de programação, assim um bocadinho (...). Já usei o Logo, mas agora o Logo está um bocadinho mais a parte, o Scratch tem muito mais potencialidades e basicamente é isso que eu uso.

Salienta ainda que utiliza apresentações em Power Point (PPT), entretanto, constata que "quando se usa PP nas aulas a atenção dos alunos não é tanta quanto quando se escreve no quadro". Uma explicação pode ser pelo fato de que os alunos "sabem que vai estar disponivel na plataforma, então, não ligam”. Essa declaração nos permitiu saber sobre a existência de um ambiente virtual de aprendizagem de apoio na instituição, que parece ser usado como repositório de materiais didáticos das disciplinas.

Fabiano enfatizou que suas escolhas metodológicas são condicionadas pelos recursos tecnológicos que dispõe. Diferentemente de Alícia, relata que sua sala tem projetor multimídia, mas não computador à disposição. É preciso levar o próprio e, embora 
a universidade tenha internet em todo o campus e não há sala com computadores com recursos para os alunos das Licenciaturas usarem.

Os dois professores se assemelham na escolha do uso de softwares, jogos e recursos tecnológicos para ensinar, Fabiano usa ainda sensores e planilhas Excel, que não foram elencados por Alicia. Ela declarou que conhece o trabalho de Fabiano, mas que "não se arrisca com os sensores como ele”, usa mesmo os softwares Geogebra e Cabri.

Fabiano ressaltou enfaticamente a dificuldade para agendar aulas nos laboratórios, pois estes são reservados para outros cursos da universidade, o que dificulta a integração de tecnologia à sua prática.

\section{CONCLUSÕES}

Foi possível identificar nas entrevistas um movimento de mudança capitaneado por esses docentes que procuram inovar suas práticas no Ensino Superior. As estratégias didáticas foram se desenvolvendo a partir da prática e do feedback dos alunos e estão estreitamente ligadas à realidade do exercício da docência de cada um deles.

As estratégias didáticas que privilegiam as interações entre os alunos têm sido utilizadas e incentivadas por esses docentes. Além disso, um ensino de cunho mais exploratório e investigativo parece ser praticado, apontando uma tendência, qual seja, a de no Ensino Superior procurar levar os estudantes (futuros professores) a um protagonismo maior durante as aulas.

Percebe-se que as estratégias didáticas, com o uso de tecnologia digital, implementadas pelos professores entrevistados, são diversificadas, dependem do conteúdo a ensinar e estão relacionadas com o feedback dos alunos a cada intervenção, o que pode explicar o fato de serem considerados docentes inovadores ao ensinar.

Em conclusão, foi possível identificar que a realidade docente pode apresentar entraves relativas às possibilidades institucionais de disponibilização de espaços adequados para uso de tecnologia na formação dos futuros professores. Entretanto, os professores entrevistados inserem no ensino softwares de apoio ao desenvolvimento de conteúdos, os enxergando como ferramentas estruturantes do pensamento do aluno. Entre as estratégias de ensino, não são dispensadas as exposições teóricas e as sistematizações, entretanto, metodologias ativas como a resolução de problemas, o uso de jogos, a programação e a utilização de materiais manipulativos nas atividades didáticas encontram- 
se inseridas na prática. Os construtos teóricos relacionados ao conhecimento especializado desenvolvido com os estudos de Didática da Matemática, das Teorias de aprendizagem e da Psicologia Cognitiva auxiliaram os professores entrevistados a elaborarem suas propostas e ações para desenvolver competências profissionais nos estudantes. $\mathrm{O}$ uso das tecnologias digitais para ensinar foi se incorporando à prática a partir de esforços próprios e de tentativas do tipo ensaio e erro, as estratégias didáticas foram se desenvolvendo a partir da prática e do feedback dos alunos.

\section{REFERÊNCIAS}

ALMEIDA, M. E. (01 de junho de 2010). Maria Elizabeth de Almeida fala sobre tecnologia na sala de aula. (E. Fernandes, Entrevistador) São Paulo, SP, Brasil: Revista Nova Escola. Disponível em: <https://gestaoescolar.org.br/conteudo/627/maria-elizabethde-almeida-fala-sobre-tecnologia-na-sala-de-aula> Acesso em 12 de out. de 2019

BECK, C. Metodologias Ativas: conceito e aplicação. Andragogia Brasil, 2018 Disponível em: $<$ https://andragogiabrasil.com.br/metodologias-ativas/>. Acesso em $12 \mathrm{de}$ out. de 2019.

BORBA, M. D. C.; PENTEADO, M. G. Informática e educação matemática. [S.1.]: Autêntica, 2001.

CASTELLS, M. A sociedade em rede. São Paulo: Paz e Terra, 1999.

COUTINHO, M. C. Metodologia de Investigação em Ciências Sociais e Humanas: Teoria e Prática. Coimbra: Almedina, 2011.

DRUCKER, P.A. Nova sociedade das organizações. In: HOWARD, R. (Org.) Aprendizado organizacional. p. 1-7. Rio de Janeiro: Campus, 2000.

FIGUEIREDO, S. A. Formação Inicial de Professores e a Integração da Prática como Componente Curricular. 1. ed. Nova Andradina: Gráfica e Editora Cristo Rei, 2017. v. 5000. $183 p$.

GIBBS, G. Análise de Dados Qualitativos. Tradução de Roberto Cataldo Costa. Porto Alegre: Artmed, 2009. 198 p. Coleção Pesquisa Qualitativa/coordenada por Uwe Flick.

GROSSECK, G.; MARINHO, S. P. P.; TÁRCIA, L. Educação a distância baseada na Web 2.0: a emergência de uma Pedagogia 2.0. Educação \& Linguagem, v.12, n.19, p. 111-123, jan./jun. 2009. Disponível em: < https://www.metodista.br/revistas/revistasims/index.php/EL/article/viewFile/816/884 > .

JONASSEN, D. H. Computadores, Ferramentas Cognitivas: Desenvolver o pensamento crítico nas escolas. Tradução de Sandra Fradão e Maria Francisca Soares Ana Rosa Gonçalves. Porto: Porto Editora, 2000.

KELLEY, T.; LITMAN, J. As 10 faces da inovação: estratégias para turbinar a criatividade. Tradução de Afonso Celso da Cunha Serra. Rio de Janeiro: Elsevier. 2007. 
LYOTARD, J.F. A condição pós-moderna. 5. ed. Rio de Janeiro:José Olympio, 1998. LOBO DA COSTA, N. M. Estratégias Didáticas de Docentes Universitários para a Formação de Futuros Professores. Atas do VI Seminário Web Currículo: Educação e Humanismo. São Paulo: PUCSP. 2019. p. (prelo).

LOBO DA COSTA, N.M.; PRADO, M.E.B.B., KFOURI, S.F. Tecnologia na Formação Continuada: uma Experiência com Tarefas Investigativas para Ensino de Geometria. Rev. Ensino Educação e Ciências Humanas, v. 18, n.2, p. 119-125, 2017.

MARINHO, S. P. P. A tecno-ausência na formação inicial do professor da educação básica na visão de docentes de licenciaturas. In: SCHWARTZ, C. M. et al. (Org.). Desafios da educação básica e pesquisa em educação. Vitória: Edufes, 2007. p. 177-199

MATTOS, J. F. Metodologias de Investigação II. Notas de Aula: Mestrado em Educação da Universidade de Lisboa, 2005.

MOREIRA, L.; LOBO DA COSTA, N. M.; RAMOS, A. Os finalistas do curso de Pedagogia no Brasil sentem-se preparados para usar as TIC em sala de aula? Colóquio Luso-Brasileiro de Educação-COLBEDUCA, v. 3, 2018. Disponível em: , http://www.revistas.udesc.br/index.php/colbeduca/article/download/13014/8325> Acesso em 12 de out. de 2019.

ONUCHIC, L. R.; ALLEVATO, N. S G. Pesquisa em Resolução de Problemas: caminhos, avanços e novas perspectivas. BOLEMA: Boletim de Educação Matemática, Vol. 25, No 41. p. 73 - 98. 2011. Disponível em

$<$ www.redalyc.org/articulo.oa?id=291223514005> Acesso em 12 de out. de 2019.

REDECKER, C. et al. European framework for the digital competence of educators: DigCompEdu. Joint Research Centre (Seville site), 2017. Disponível em: < https://ec.europa.eu/jrc/en/publication/eur-scientific-and-technical-researchreports/european-framework-digital-competence-educators-digcompedu $>$. Acesso em 12 de out. de 2019.

REDING, V. The disruptive force of Web2.0: how the new generation will define the future. In: Youth Forum, ITU Telecom World Hong Kong, China, 3 December 2006 Disponível em:

$<$ http://europa.eu/rapid/pressReleasesAction.do?reference=SPEECH/06/773\& format=PD F\&aged $=0$ \&language $=E N \&$ guiLanguage $=$ en $>$. Acesso em 12 de out. de 2019.

TAROZZI, M. O que é Grounded Theory?: Metodologia de pesquisa e teoria fundamentada nos dados. Tradução de Carmem Lussi. Petrópolis: Vozes, 2011.

TOFFLER, A. Powershift: as mudanças do poder. Rio de Janeiro: Record, 1990.

UNESCO ICT competency standards for teachers Paris: United Nations Educational, Scientific and Cultural Organization, 2008. Disponível em: $<$ http://cst.unescoci.org/sites/projects/cst/The\%20Standards/ICTCSTPolicy\%20Framework.pdf $>$ Acesso em 12 de out de 2019.

Submetido em 21 de outubro de 2019. Aprovado em 24 de janeiro de 2020. 